\title{
Sea surface slope as a proxy for Agulhas Current strength
}

\author{
Erik van Sebille, ${ }^{1}$ Lisa M. Beal, ${ }^{1}$ and Arne Biastoch ${ }^{2}$ \\ Received 8 February 2010; revised 19 April 2010; accepted 20 April 2010; published 15 May 2010.
}

[1] The linear relation between the strength of the Agulhas Current at nominal latitude $34^{\circ} \mathrm{S}$ and the gradient in sea level height anomaly across the current is investigated in a $1 / 10^{\circ}$ resolution regional numerical ocean model. Our results show that the strength of the current can be estimated with reasonable accuracy using altimeter data, once it has been calibrated using in-situ transport measurements. Three years of transport measurements provide a calibration with worst-case correlation $R=0.78$. In that case the errors in proxy transport have a standard deviation of $9.8 \mathrm{~Sv}$, compared to a $20.2 \mathrm{~Sv}$ standard deviation of the transport time series itself. From these results we conclude that the design of the Agulhas Current Timeseries (ACT) experiment, a three-year deployment of moorings across the Agulhas Current and along a TOPEX/ Jason altimeter ground track, will likely produce a good quality multi-decadal time series of Agulhas Current strength. Citation: van Sebille, E., L. M. Beal, and A. Biastoch (2010), Sea surface slope as a proxy for Agulhas Current strength, Geophys. Res. Lett., 37, L09610, doi:10.1029/2010GL042847.

\section{Introduction}

[2] The Agulhas Current, the western boundary current of the southern Indian Ocean gyre, is among the strongest in the world ocean [e.g., De Ruijter et al., 1999a; Lutjeharms, 2006]. The current feeds into the Agulhas Retroflection located south of Africa, where approximately $20-30 \%$ of the water carried by the current enters the Atlantic Ocean as Agulhas leakage while the rest circulates back into the Indian Ocean.

[3] On interannual time scales, the magnitude of Agulhas leakage seems to be related to the strength of the Agulhas Current. Rouault et al. [2009] show in a $1 / 4^{\circ}$ numerical model that in the last twenty years both the Agulhas Current volume flux and the magnitude of Agulhas leakage have increased. Van Sebille et al. [2009], on the other hand, use a $1 / 10^{\circ}$ numerical model to demonstrate that there is an anticorrelation between Agulhas Current strength and the magnitude of Agulhas leakage, whereas the correlation is positive in the $1 / 2^{\circ}$ version of the same model. The difference in behaviour might be related to the degree to which the Agulhas Current Retroflection is controlled by inertia [Dijkstra and De Ruijter, 2001]. According to Ou and De Ruijter [1986], an inertially-controlled Agulhas Current can separate from the continental slope through outcropping of isopycnals, which leads to a free jet upstream of the

\footnotetext{
${ }^{1}$ Rosenstiel School of Marine and Atmospheric Science, University of Miami, Miami, Florida, USA.

${ }^{2}$ Theory and Modeling Division, Leibniz Institute of Marine Sciences, Kiel, Germany.

Copyright 2010 by the American Geophysical Union. 0094-8276/10/2010GL042847
}

southern tip of Africa. The intermediate-resolution numerical model of Rouault et al. [2009] may be controlled by viscosity, in which case the current might detach from the slope too far southward and have an unrealistic retroflection.

[4] The anticorrelation between Agulhas leakage and Agulhas Current transport, found in the high-resolution model, could be exploited in the monitoring of the Agulhas leakage. Measuring Agulhas leakage is difficult in the turbulent Cape Basin where Indian Ocean water vigorously mixes with water from the Atlantic and Southern Ocean [Boebel et al., 2003]. Measuring the strength of the Agulhas Current, on the other hand, is much easier because of its linearity and its confinement to the African continental slope.

[5] The Agulhas Current Timeseries (ACT) experiment has been established to obtain a multi-decadal proxy of Agulhas Current transport using altimeter data, similar to the Kuroshio transport time series [Imawaki et al., 2001]. The experiment consists of two phases. In the first phase, a mooring array measuring the velocity structure of the current will be deployed for a period of three years. This will yield an estimate of interannual variability of Agulhas Current strength and structure. In the second phase, the sea surface height along the ACT section, obtained from satellite altimetry, will be regressed onto the in-situ measured Agulhas Current transport. If this relation is statistically significant, then the three-year long observed Agulhas Current transport can be extended to a time series with the length of the altimeter mission record (i.e. from 1992 to present-day and continuing). To optimally facilitate the regression of observed transport and altimetry, the ACT section is collocated with a TOPEX/Jason track at nominally $34^{\circ} \mathrm{S}$. At this latitude the Agulhas is farther offshore on average than at the historical $32^{\circ} \mathrm{S}$ section [Bryden et al., 2005], so that contamination of coastal altimeter data is less of a problem.

[6] In the study presented here, the merits of both phases of the ACT experiment are tested before the instruments are put into the water. We have investigated how well the array captures the Agulhas Current transport, and how much skill there is in the altimeter proxy. For this purpose, a virtual version of the mooring array is deployed within a highresolution numerical ocean model.

\section{Obtaining a Transport Time Series}

[7] The numerical model used is the AG01 model, a 1/10 numerical ocean model of the greater Agulhas region $\left(20^{\circ} \mathrm{W}-\right.$ $\left.70^{\circ} \mathrm{E} ; 47^{\circ} \mathrm{S}-7^{\circ} \mathrm{S}\right)$, nested into a $1 / 2^{\circ}$ global ocean-sea-ice model. Both models are based on NEMO (version 2.3) [Madec, 2006]. The models are two-way nested, allowing for information to cross the open boundaries both ways [Debreu et al., 2008]. In this way, the local dynamics in the Agulhas region is affected by the global circulation and vice 

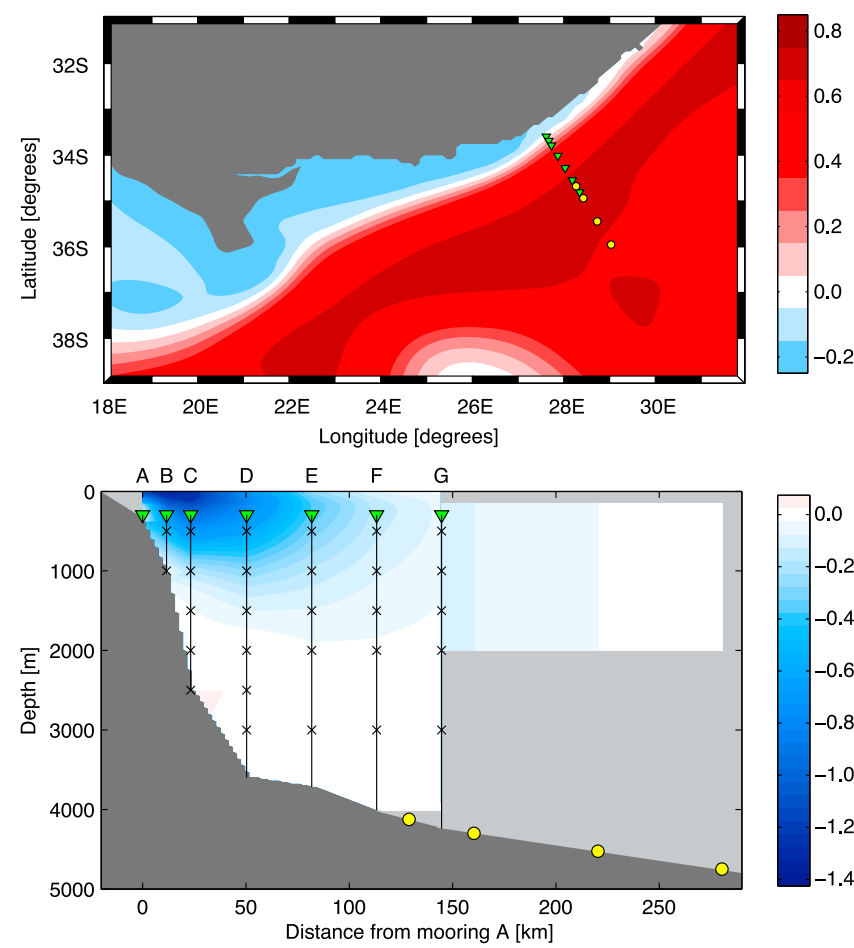

Figure 1. (top) The model mean sea surface height in the Agulhas Region (in $\mathrm{m}$ ) over the 25 years used in the analysis. The green triangles and yellow circles denote the locations of the moorings and the C-PIES, respectively. (bottom) From the instruments on these moorings, the 25year mean velocity profile across the Agulhas Current in the numerical model can be determined (in $\mathrm{m} / \mathrm{s}$ ). The crosses are current meters, the green triangles are upward looking ADCPs, and the yellow circles are C-PIES. These latter yield only column-integrated transports between $200 \mathrm{~m}$ and $2000 \mathrm{~m}$ depth, and hence no vertical structure. Above and below that, there is no velocity information.

versa. The models are run using the CORE data set of daily wind and surface forcing fields and the last 25 years of fiveday mean output are used for the analysis here. The skill of the model has been confirmed in numerous studies [e.g., Biastoch et al., 2008], with a mean Agulhas leakage of $17 \mathrm{~Sv}$. Bryden et al. [2005] report an Agulhas Current strength of $78.6 \pm 19.7 \mathrm{~Sv}$ from their mooring array, while the model has an Agulhas Current strength of $73.3 \pm$ 7.2 Sv for the same period [Biastoch et al., 2009a]. The model also includes a realistic Agulhas Undercurrent [Beal, 2009] and periodicity of the dominant meander mode (Natal pulses, e.g., De Ruijter et al. [1999b]).

[8] The ACT array will consist of seven full-depth current meter moorings out to $160 \mathrm{~km}$ offshore, extended by four C-PIES sensors an additional $190 \mathrm{~km}$ offshore (Figure 1). Each mooring is topped with an Acoustic Doppler Current Profiler to accurately measure the large velocity gradients in the top $300 \mathrm{~m}$, and has additional single point current meters between $500 \mathrm{~m}$ depth and the ocean floor. In the model, the time series recorded by the instruments of the array are simulated by linearly interpolating the model velocity field onto the locations of the instruments. From these virtual instrument time series, velocities are gridded using a combination of shape-preserving spline interpolation and extrapolation, in a similar method as employed by Johns et al. [2005].

[9] As we are interested in a time series of Agulhas Current strength, the southwestward values of the interpolated fields are summed for a time series of downstream transport between moorings A and G. This time series has a correlation $R=0.79$ with the downstream Eulerian transport time series on the native model grid (Figure 2) and is significant at a $95 \%$ confidence level. However, the flux from the Agulhas Current is often greatly underestimated by the current meter mooring array, introducing a bias in the absolute transport estimate. Only $0.3 \%$ of the downstream Eulerian transport flows inshore of mooring A, but $10 \%$ flows offshore of mooring $\mathrm{G}$.

[10] This offshore flow is accounted for by the C-PIES sensors, which record pressure, bottom velocity, and acoustic travel time. These can be used to estimate geostrophic transport from the gradient in geopotential height [e.g., Baker-Yeboah et al., 2009]. Mimicking C-PIES sensors in a numerical model is not straightforward, as the postprocessing of the real data involves an empirical relationship between geopotential height and acoustic travel time, which is obtained from hydrographic sections. Using regional hydrographic data, we estimate that the error in transport between $200 \mathrm{~m}$ and $2000 \mathrm{~m}$ from the C-PIES data will be no more than $20 \%$. Using a worst case scenario, the C-PIES transport time series is here computed as the exact transport on the model grid, multiplied by a normally distributed random number with mean $\mu=1$ and standard deviation $\sigma=0.2$. For values between $\sigma=0.1$ and $\sigma=0.4$ all numbers presented in this study change by less than $5 \%$.

[11] When the time series of the virtual C-PIES is added to the time series of the current meter array, the correlation with the transport time series on model grid increases somewhat, to 0.81 (Figure 2). More importantly, the bias in transport is greatly reduced, as the RMS error between the two time series decreases by $20 \%$.

\section{Verifying the Relation With Altimetry}

[12] The objective of the ACT experiment is to find a relation between the gradient in sea surface height and the
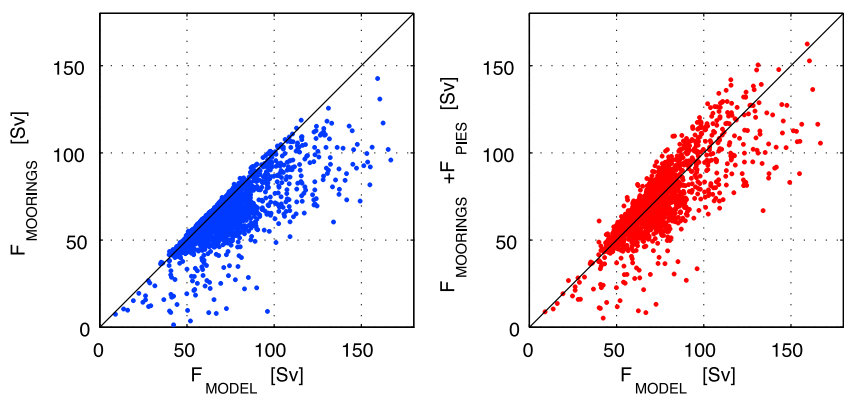

Figure 2. (left) A scatter plot of the volume flux as measured by current meter moorings $A-G$ versus the Agulhas Current volume flux on the native model grid. The correlation between the two time series is 0.79 (significant at the $95 \%$ confidence level) with an RMS error of $15.5 \mathrm{~Sv}$. It is clear that the volume flux is systematically underestimated by the current meter mooring array. (right) If the information from the C-PIES is included, the relation becomes less biased $(R=0.81$, RMS error $12.4 \mathrm{~Sv})$. 

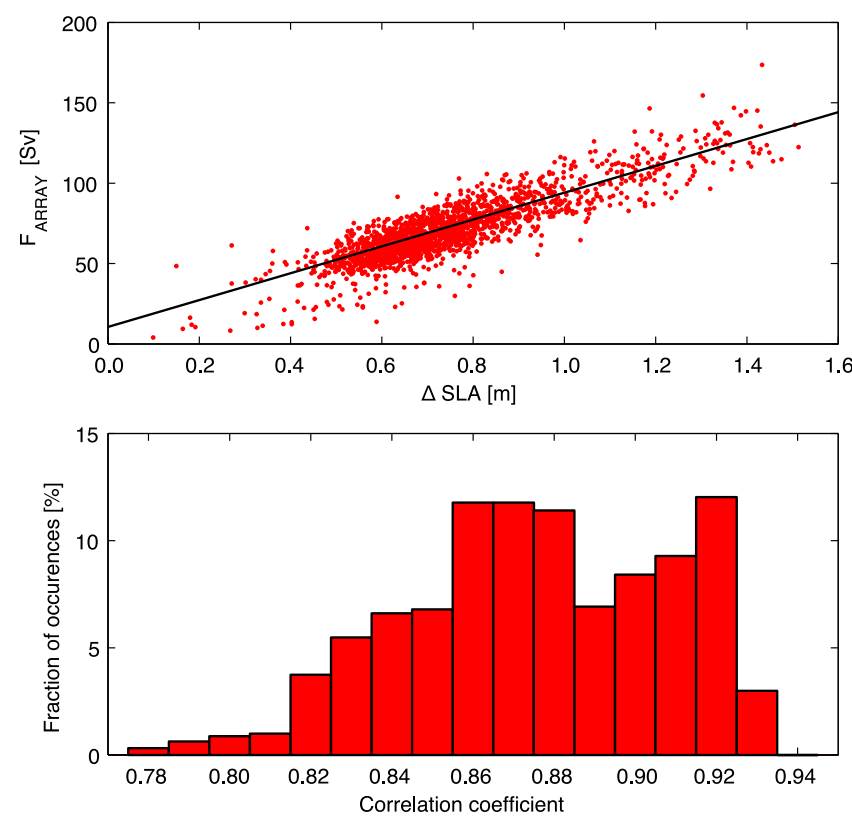

Figure 3. (top) A scatter plot of $F_{A R R A Y}$, the transport across the section, versus the difference in anomalous sea surface height on the ACT track, using all 25 years of data. The correlation is 0.87 , the best linear fit is shown by the black line. (bottom) To investigate the merits of using only three years of data, a histogram of correlation coefficients using three-year long subsets of the full time series is computed. In this model, the correlation coefficient is at least 0.78 , and can go up to 0.93 . Within the context of this model a three year long time series is sufficient to obtain a regression between transport and $\triangle$ SLA.

Agulhas Current transport, with the goal to extend the transport time series using altimetry. Ignoring effects due to the varying ocean depth, geostrophy yields:

$$
F_{A L T}=a \Delta \mathrm{SLA}+b
$$

where $F_{A L T}$ is the volume flux of the Agulhas Current obtained from altimetry, $\triangle \mathrm{SLA}$ is the difference in sea level anomaly across the ACT section, and $a$ and $b$ are the calibration constants obtained from a regression of $\triangle$ SLA on the transport $F_{A R R A Y}$ as measured by the combination of current meter array and C-PIES. $\triangle$ SLA is used instead of $\triangle \mathrm{SSH}$ (the gradient in sea surface height) since the former does not require knowledge of the geoid, which is poorly resolved in this region [Vossepoel, 2007]. Note, however, that $\triangle \mathrm{SSH}$ and $\triangle \mathrm{SLA}$ differ only by a constant, which can always be absorbed in $b$.

[13] To test the validity of relation (1) and thus the feasibility of extending the ACT transport time series using the altimeter record, the correlation between $F_{A R R A Y}$ and $F_{A L T}$ in the model is computed. The highest correlation, $(R=0.87)$, is found when $\triangle \mathrm{SLA}$ is computed using the difference between SLA at mooring A and SLA $180 \mathrm{~km}$ farther offshore (Figure 3), using all available 25 years of data.

[14] The method is good when using 25 years of data, but in reality we will only have three years of mooring data. The question is how good the method will be in that case. To assess what kind of correlations can be expected using three year time series, the data is partitioned by moving a three year window through the full 25 year time series. The resulting 1605 correlations between $F_{A R R A Y}$ and $F_{A L T}$ yield values of $R$ ranging from 0.78 to 0.93 (Figure 3). All of these are significant at the $95 \%$ confidence level. Furthermore, all regression coefficients of the short time series lie within the $95 \%$ confidence bounds of the regression of the 25 year time series.

[15] The accuracy of the estimate is adequate (Figure 4). Even in the scenario with lowest correlation, the difference between $F_{A L T}$ and $F_{A R R A Y}$ has a standard deviation of $9.8 \mathrm{~Sv}$ and most variability is captured. The standard deviation in $F_{A R R A Y}$ itself is more than twice as large at $20.2 \mathrm{~Sv}$, on a mean transport of 71.2 Sv. These standard deviations are for the five-day resolution time series; if the time series are smoothed to yearly values the standard deviation of the error in the estimate reduces to $2.4 \mathrm{~Sv}$.

\section{Conclusions and Discussion}

[16] In the coming years, an experiment will be conducted where the transport of the Agulhas Current is monitored using a combination of velocity-sensor equipped moorings and C-PIES. Once a three-year long time series of transport is obtained, it can be used to calibrate a scheme where the cross-current gradients in anomalous sea surface height may be used to extend the transport time series from 1992 onward. In this study, the mooring design of this Agulhas Current Timeseries (ACT) experiment has been implemented in a numerical model to assess its feasibility in the real ocean.

[17] The spacing of the moorings and instruments seems to be sufficient for the array to measure almost all volume transport through it. On the occasions that the Agulhas Current is so far offshore that there is considerable transport beyond the outer mooring, four additional C-PIES help in monitoring the current transport. Once the three year time series of Agulhas Current transport is obtained, it can be regressed onto the time series of altimeter data to yield an
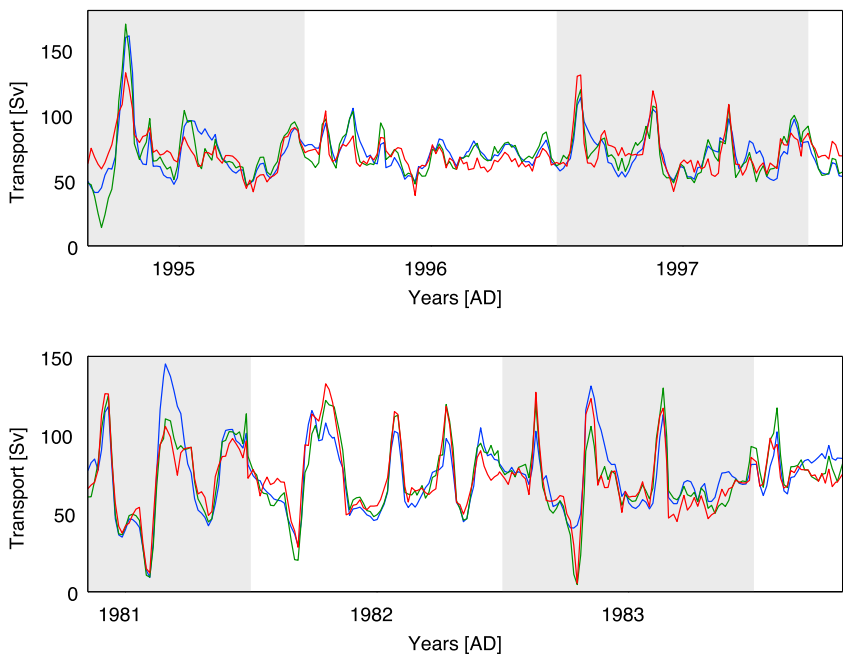

Figure 4. (top) Comparison between three-year time series of $F_{M O D E L}$ in blue, $F_{A R R A Y}$ in red, and $F_{A L T}$ in green, with the lowest correlation between $F_{A R R A Y}$ and $F_{A L T}(R=$ $0.78)$, and (bottom) the highest correlation $(R=0.93)$. In either case, most variability on five day interval is captured by the ACT experiment. 
empirical relationship of transport as a function of $\Delta$ SLA. In this numerical model, the correlation between the Agulhas Current transport and the gradient in sea level anomaly is better than $R=0.78$ for any three-year measuring period.

[18] Note that it might be possible to improve the correlation between altimetry and current transport by introducing regressions more sophisticated than $\triangle$ SLA. One way to improve the correlation might be to introduce a weight to the local gradient in sea level anomaly corresponding to the typical depth of the Agulhas Current at that location, which will be known from the mooring array data and hydrographic sections. Another way would be to make the endpoints of $\triangle$ SLA dependent on the structure of SLA itself. In any case, the values cited in this study are lower bound estimates and might be improved when the real data has been obtained.

[19] Given the important role of the Agulhas region in the global ocean circulation [e.g., Biastoch et al., 2009b], a multi-decadal time series of observed Agulhas Current strength variability is an important asset in the Global Ocean Observing System. From this study, it seems that the Agulhas Current Timeseries experiment is apt to deliver such a time series.

[20] Acknowledgments. Model and float integrations have been performed at the Höchstleistungsrechenzentrum Stuttgart (HLRS).

\section{References}

Baker-Yeboah, S., D. R. Watts, and D. A. Byrne (2009), Measurements of sea surface height variability in the eastern South Atlantic from pressure sensor-equipped inverted echo sounders: Baroclinic and barotropic components, J. Atmos. Ocean. Tech., 26, 2593-2609.

Beal, L. M. (2009), A time series of Agulhas Undercurrent transport, J. Phys. Oceanogr., 39, 2436-2450.

Biastoch, A., C. W. Böning, and J. R. E. Lutjeharms (2008), Agulhas leakage dynamics affects decadal variability in Atlantic overturning circulation, Nature, 456, 489-492.

Biastoch, A., L. M. Beal, J. R. E. Lutjeharms, and T. G. D. Casal (2009a), Variability and coherence of the Agulhas Undercurrent in a high-resolution ocean general circulation model, J. Phys. Oceanogr., 39, 2417-2435.

Biastoch, A., C. W. Böning, F. U. Schwarzkopf, and J. R. E. Lutjeharms (2009b), Increase in Agulhas leakage due to poleward shift of Southern Hemisphere westerlies, Nature, 462, 495-499.
Boebel, O., J. R. E. Lutjeharms, C. Schmid, W. Zenk, T. Rossby, and C. N. Barron (2003), The Cape Cauldron, a regime of turbulent inter-ocean exchange, Deep Sea Res., Part II, 50, 57-86.

Bryden, H. L., L. M. Beal, and L. M. Duncan (2005), Structure and transport of the Agulhas Current and its temporal variability, J. Oceanogr., 61, 479-492.

De Ruijter, W. P. M., A. Biastoch, S. S. Drijfhout, J. R. E. Lutjeharms, R. P. Matano, T. Pichevin, P. J. Van Leeuwen, and W. Weijer (1999a), Indian-Atlantic interocean exchange: Dynamics, estimation, and impact, J. Geophys. Res., 104, 20,885-20,910, doi:10.1029/ 1998JC900099.

De Ruijter, W. P. M., P. J. Van Leeuwen, and J. R. E. Lutjeharms (1999b), Generation and evolution of Natal pulses: Solitary meanders in the Agulhas Current, J. Phys. Oceanogr., 29, 3043-3055.

Debreu, L., C. Vouland, and E. Blayo (2008), AGRIF: Adaptive grid refinement in Fortran, Comput. Geosci., 34, 8-13.

Dijkstra, H. A., and W. P. M. De Ruijter (2001), On the physics of the Agulhas current: Steady retroflection regimes, J. Phys. Oceanogr., 31, 2971-2985.

Imawaki, S., H. Uchida, H. Ichikawa, M. Fukasawa, S. Umatani, and the ASUKA Group (2001), Satellite altimeter monitoring the Kuroshio transport south of Japan, Geophys. Res. Lett., 28, 17-20, doi:10.1029/ 2000GL011796.

Johns, W. E., T. Kanzow, and R. Zantopp (2005), Estimating ocean transports with dynamic height moorings: An application in the Atlantic Deep Western Boundary Current at $26^{\circ} \mathrm{N}$, Deep Sea Res., Part I, 52, $1542-$ 1567.

Lutjeharms, J. R. E. (2006), The Agulhas Current, Springer, New York.

Madec, G. (2006), NEMO ocean engine, in Note du Pôle de Modélisation, Inst. Pierre Simon Laplace, Paris.

Ou, H. W., and W. P. M. De Ruijter (1986), Separation of an inertial boundary current from a curved coastline, J. Phys. Oceanogr., 16, 280-289.

Rouault, M., P. Penven, and B. Pohl (2009), Warming in the Agulhas Current system since the 1980 's, Geophys. Res. Lett., 36, L12602, doi:10.1029/2009GL037987.

Van Sebille, E., A. Biastoch, P. J. Van Leeuwen, and W. P. M. De Ruijter (2009), A weaker Agulhas Current leads to more Agulhas leakage, Geophys. Res. Lett., 36, L03601, doi:10.1029/2008GL036614.

Vossepoel, F. C. (2007), Uncertainties in the mean ocean dynamic topography before the launch of the Gravity Field and Steady-State Ocean Circulation Explorer (GOCE), J. Geophys. Res., 112, C05010, doi:10.1029/ 2006JC003891.

L. M. Beal and E. van Sebille, Rosenstiel School of Marine and Atmospheric Science, University of Miami, 4600 Rickenbacker Causeway, Miami, FL 33149, USA. (evansebille@rsmas.miami.edu)

A. Biastoch, Theory and Modeling Division, Leibniz Institute of Marine Sciences, Duesternbrooker Weg 20, D-24105 Kiel, Germany. 